\title{
Non-linearities in inflation-growth nexus in the SADC region: A panel smooth transition regression approach
}

\author{
Monaheng Seleteng *, Manoel Bittencourt, Reneé van Eyden \\ Department of Economics, University of Pretoria, Pretoria, South Africa
}

\begin{abstract}
A B S T R A C T
The main objective of central banks around the world is the achievement and maintenance of price stability, which actually creates an environment conducive for faster economic growth. Therefore, it is important for policy makers to understand the relationship between inflation and economic growth in order to make sound policies. If inflation is detrimental to economic growth, then policy makers should aim for low rates of inflation. This leads to a question; how low should the inflation rate be? Previous research in the non-linearities of the inflation-growth relationship has found that a positive relationship exists when the in-flation rate is low and a negative relationship when the inflation rate is high. This implies the existence of a threshold level of inflation at which the sign switches. In this paper we use panel data for the period 1980-2008 to examine the inflation-growth nexus in the Southern African Development Community (SADC) re-gion and to endogenously determine the threshold level of inflation. To deal with problems of endogeneity and heterogeneity, the paper uses the Panel Smooth Transition Regression (PSTR) method developed by González et al. (2005) to examine the non-linearities in the inflation-growth nexus. This technique further estimates the smoothness of the transition from a low inflation to a high inflation regime. The findings reveal a threshold level of $18.9 \%$, above which inflation is detrimental to economic growth in the SADC region.
\end{abstract}

Keywords:

Economic gowth

Inflation

Threshold level

Non-linearities

PSTR model

\section{Introduction}

The primary objective of macroeconomic policies is to attain high and sustainable output growth rates coupled with low and stable inflation rates (Kan and Omay, 2010), implying that a certain magnitude of inflation is necessary to "grease the wheels" of the economy (Temple, 2000). Therefore, policy makers find it important to understand this re-lationship in order to ensure sound policy making. If inflation is detri-mental to economic growth, it follows that policy-makers should aim for low rates of inflation. Therefore, this leads to the question; how low should the inflation rate be? That is, at what level of inflation does the relationship between inflation and economic growth become negative (Furuoka et al., 2009). Previous empirical research in this field has shown a positive relationship between these two variables to exist when the inflation rate is low and a negative relationship when the inflation rate is high, hence implying that there is an optimal level, or a threshold level of inflation, at which the sign switches from positive to negative. Such studies include, amongst others; Sarel, 1996; a n d Ghosh and Phillips, 1998; who advocate that inflation has a detrimental

\footnotetext{
* Corresponding author. Tel.: +27 124203459.

E-mail addresses: monaheng.seleteng@up.ac.za, mseleteng@yahoo.co.uk (M. Seleteng), manoel.bittencourt@up.ac.za (M. Bittencourt), renee.vaneyden@up.ac.za (R. van Eyden).
}

effect on economic growth, after reaching a threshold level of $8 \%$ and $2.5 \%$, respectively and therefore monetary policy should aim at achieving a low level of inflation.

The above-mentioned studies include both linear and non-linear approaches to modelling. In some instances, the threshold levels are exogenously determined, for instance, Fischer (1993) and; Bruno and Easterly (1998). Also, in certain cases, the unobserved heterogeneity at both country and time dimensions is not accounted for. The contribution of this paper is therefore to estimate the threshold level endogeneously and also to estimate the smoothness of the transition from a low to a high inflation regime. We adopt a relatively new econometric technique, Panel Smooth Transition Regression (PSTR), for threshold estimation and inference developed by González et al. (2005) which addresses the problems of endogeneity and heterogeneity in a non-linear framework. To the best of my knowledge, non-linearities in the inflation-growth relationship has never been investigated in the Southern African Development Community (SADC) context, hence this warrants further investigation so as to ascertain if a similar relationship as in developed countries exists.

The purpose of the paper is to precisely estimate the threshold level of inflation below which inflation may not have any impact, or a positive impact, on economic growth or above which inflation may be detrimental to economic growth, using panel data for the period 19802008.

The organisation of the paper is as follows: Section 2 provides a re-view of the literature. Section 3 focuses on the research methodology and data description. Empirical results are contained 
in Section 4, w h i l e concluding remarks are presented in Section 5.

\section{Literature review}

Non-linearities in the inflation-growth nexus have attracted interest among economic researchers in recent years. Research in this field has however provided mixed results, largely depending on the methodology used. Furthermore, thresholds also vary substantially when analysing developed and developing countries respectively, implying that the level of development in countries under consideration may be an important factor.

One of the first papers to examine the possibility of non-linearities in the inflation-growth nexus is that of Fischer (1993). Using a panel of ninety-three countries consisting of both developed and developing countries, Fischer uses spline regression techniques and arbitrarily di-vides the sample into three threshold levels or breaks, namely inflation rates less than $15 \%$, inflation rates between $15 \%$ and $40 \%$, and inflation rates above $40 \%$. The results depict the presence of non-linearities in the relationship between inflation and growth. However, the fact that the thresholds are determined exogenously by dividing the sample ar-bitrarily by using breaks to represent the thresholds presents a limita-tion in this case. Similarly, Bruno (1995) investigates the inflation-growth relationship among 127 countries (consisting of both developed and developing countries) and finds that growth rates only decline when inflation rates move beyond 20 $25 \%$ and that growth increases as inflation rises up to the $15-20 \%$ range.

Furthermore, Sarel (1996) tests for structural breaks in the inflation-growth relationship using panel data for eighty-seven coun-tries for the period 1970-1990. The results reveal a significant structural break at an annual inflation rate of $8 \%$, implying that below this rate, inflation does not have a significant effect on growth, while above $8 \%$ inflation has a negative and statistically significant impact on growth. Bruno and Easterly (1998) also examine the de-terminants of economic growth using data from twenty-six coun-tries during the period 1961-1992. They exogenously determine the threshold level of inflation as $40 \%$ and find the interrelationship between inflation and growth to be inconclusive. Furthermore, Ghosh and Phillips (1998) consider data for 145 countries for the pe-riod 1960-1996 and combine a non-linear treatment of the inflation growthrelationship with an extensive examination of robustness. Their findings reveal the existence of a statistically significant threshold level of $2.5 \%$ above which inflation negatively affects growth. The study also find that the inflation-growth relation is con-vex, so that the decline in growth associated with an increase from 10 to $20 \%$ in the inflation rate is much larger than that associated with moving from 40 to $50 \%$.

In addition, Khan and Senhadji (2001) estimate the threshold levels separately for industrial and developing countries using a panel of 140 countries for the period 1960-1998. They make use of non-linear least squares (NLLS) estimation and find the threshold levels to be $1-3 \%$ and $11-12 \%$ for industrial and developing countries, respectively. Their results suggest that the inflation level below these threshold levels have no effect on growth, while inflation rates above these levels have a significant negative impact on growth. Similarly, Moshiri and Sepehri (2004) use a non-linear specification and the data from four groups of countries at various stages of development and examine the possibility of various thresholds (rather than a single threshold) across countries at various stages of development. They found the thresholds levels varying widely from as high as $15 \%$ per year for lower middle-income countries to $11 \%$ for low-income countries, and 5\% for upper-middle income countries. Their results also depict no statistically significant relationship between inflation and economic growth in the Organisation for Economic Cooperation and Development (OECD) countries.

A similar study is also carried out by Lee and Wong (2005), who uses a threshold regression model to investigate the existence of inflation thresholds for Taiwan and Japan using data for the period
1962-2002 for Taiwan and 1970-2001 for Japan, respectively. The results suggest threshold levels of $7.25 \%$ for Taiwan and $9.66 \%$ for Japan. Drukker et al. (2005) investigate the non-linearities in the inflation-growth rela-tionship using data of 138 countries over the period 1950-2000. The re-sults reveal one threshold value of $19.16 \%$, below which inflation do not have a statistically significant effect on growth and above which infla-tion has a negative and statistically significant impact on long-run growth.

In addition, a study by Pollin and Zhu (2006) report the existence of a non-linear relationship between inflation and economic growth for 80 countries over the 1961-2000 period, using middle-income and lowincome countries. The paper finds an inflation threshold of between 15 and $18 \%$, above which inflation is detrimental to economic growth and below which inflation is beneficial to economic growth. Similarly, Li (2006) estimates a non-linear relationship between inflation and economic growth for 27 developing and 90 developed countries over the 1961-2004 period. The results reveal two threshold levels of $14 \%$ and $38 \%$ for developing countries. When the inflation rate is below $14 \%$, the ef-fects of inflation on growth are positive and insignificant. Between 14 and 38 $\%$, th ee ffects arestronglyn ega tivean dsign ificant and above 38\% the ef-fects diminish but remain significantly negative. Furthermore, the study reveal a threshold level of $24 \%$ for developed countries, above which the effects of inflationong rowth $\mathrm{r}$ e $\mathrm{m}$ a in sign i ficantly negative, but the mar-ginal effect of infla $t$ ion on growth dimin ish es.

Furthermore, Schiavo and Vaona (2007) use a nonparametric estimator and semiparametric instrumental variable (IV) estimator to assess the non-linearities between inflation and economic growth, and also the existence of a threshold level of inflation. They use a dataset for 167 countries (comprising of developed and developing countries) cov-ering the period 1960-1999. The results reveal the existence of a thresh-old level of $12 \%$ for developed countries, where below this level, inflation seems not to be harmful to growth, while it is harmful above the $12 \%$ level. Due to high variability of growth performances in developing countries, the study did not find a precise threshold level of inflation for the group of countries included in the analysis. Similarly, Furuoka et al. (2009) tests for the existence of threshold effects in the inflation-growth relationship in the context of Malaysia, using endogenous threshold autoregressive (TAR) models proposed by Hansen (1999). The study uses annual data covering the period 1970-2005 and finds a threshold level of $3.89 \%$ above which inflation significantly retards growth of GDP and below which inflation is positive and significantly re-lated to growth. On the other hand, Espinoza et al. (2010) use a smooth transition regression (STR) model to investigate the speed at which infla-tion beyond a threshold becomes harmful to growth. The study employs a panel of 165 countries covering the period 1960-2007. The results show that inflation above a threshold of $10 \%$ and $1 \%$ quickly becomes harmful to growth; for emerging economies and advanced economies, respectively.

In a recent paper, Kan and Omay (2010), re-examine the threshold effects in the inflation-growth nexus with a panel of six industrialised economies (Canada, France, Italy, Japan, UK and US) covering the period 1972-2005. They use panel smooth transition regression (PSTR) which takes into account the non-linearities in the data. They also control for unobserved heterogeneity in both cross-section and time dimensions. The results reveal a threshold level of $2.52 \%$, above which inflation neg-atively and significantly affects economic growth. Similarly, Ibarra and Trupkin (2011) also use a PSTR model with fixed effects to investigate the non-linearities in the inflation-growth nexus among 120 countries for the period 1950-2007. Their results depict a threshold level of $19.1 \%$ for non-industrialised countries and a high speed of transition from low to high inflation regimes. By the same token, Mignon and Villavicencio (2011) also rely on a PSTR model to investigate the non-linearities in the inflation-growth relationship among 44 countries covering the pe-riod 1961-2007 and find a threshold level of $19.6 \%$ for lower-middle and low-income countries. 
On a different note, Eggoh (2010) investigate the linkage between fi-nancial development and economic growth using PSTR for 71 countries, comprising both developed and developing countries, from 1960 to 2004. The findings reveal that the relationship between financial devel-opment and economic growth is nonlinear. The results specifically show that inflation, the ratio of government expenditures to GDP, de-gree of openness to trade and financial development affects the nonlinearity between financial development and growth. Furthermore, Eggoh (2011) examine the inflation effects on finance and growth using a similar data set and PSTR methodology. The findings reveal an infla-tion threshold of $20 \%$, above which economic growth is not affected, or negatively affected by financial development. The study also finds that the impact of financial development on growth is positive and sig-nificant for inflation below the $10 \%$ level

In the SADC context, research in inflation-growth nonlinearities is limited to a few country level studies. For instance, Hodge (2006) uses a South African data to test whether the data supports the findings of other cross-section studies that inflation has a nega-tive effect on growth over the longer term. He further investigates whether higher economic growth can be gained at the cost of higher inflation in the short run. The study makes use of annual data from 1950 to 2002. The findings of the study reveal that inflation retards economic growth in the long run in South Africa. Similarly, Phiri (2010) investigates the inflation threshold level that is detrimental to finance-growth activity for the South African economy. He uses quarterly data for the period 2000 to 2010 and the results reveal an inflation threshold level of $8 \%$. Furthermore, Leshoro (2012) reexamined the inflation-growth relationship in South Africa using quarterly data for the period 1980 to 2010 . He adopts the threshold regression model developed by Khan and Senhadji (2001) and estimates an inflation threshold level of $4 \%$, below which there is a positive but statistically insignificant relationship between inflation and growth, and above which the relationship be-comes negative and significant.

Several observations can be highlighted from the literature discussed above. Firstly; there seems to be consensus that the inflation-growth relationship is non-linear, implying the existence of a threshold level of infla t i o $\mathrm{n}$ b e l o w w h i c h i n flation has either no significant impact, or a pos-itive impact on growth, and above which inflation has a negative impact on economic growth. The threshold level(s) vary from country to coun-try depending on the stage of economic development, institutional ar-rangements and structural realities. Secondly, developing countries seem to have higher threshold levels as compared to developed countries and this is largely attributable to the sound macroeconomic policies being implemented by the latter. Therefore, since the SADC region comprises of developing countries, it is expected that the threshold level would be around the same range as that found by previous research in this field such as Ibarra and Trupkin (2011), a n d Mignon and Villavicencio (2011), who found a threshold level of $19.1 \%$ and $19.6 \%$ for developing countries, respectively. Therefore, there seems to be a consensus that high inflation rates will have a negative impact on growth, and this turning point (threshold level) will most likely be reached once inflation exceeds 15 to 20\% (Heintz and Ndikumana, 2011). Thirdly, the choice of estimation model and robustness check also play an important role in examining the non-linearities in the infla-tion-growth nexus.

Attractive models in the panel data context are those that in addition to accounting for non-linearities between the variables, also account for problems such as endogeneity and heterogeneity, hence this paper adopts the PSTR model developed by González et al. (2005) in investigating the non-linearities in the inflation-growth nexus. An important limitation of previous studies investigating the nonlinearities of the inflation-growth nexus is that, the samples were arbitrarily divided using breaks that represent the thresholds, meaning that threshold levels were exogenously determined, for instance, Fischer (1993). Therefore, the main contribution of this paper is to determine the threshold levels endogenously. Furthermore, the study also investigates the speed of the transition from one inflation regime to another.

\section{Methodology and data}

\subsection{Panel smooth transition regression model}

This section describes the model specification and the data being used to assess the non-linearity of the relationship between inflation and economic growth. The paper adopts the PSTR approach developed by González et al. (2005) which caters for the heterogeneity problem in a non-linear framework. A PSTR model is a fixed effects model with exogenous regressors. The model is therefore a panel model with coef-ficients that vary across individuals and over time,

The PSTR model is the extension of a smooth transition regression (STR) modelling to panel data with heterogeneity across the panel members and over time (Chang and Chiang, 2011). It allows for hetero-geneity in the regression coefficients by assuming that coefficients are continuous functions of an observable variable through a bounded func-tion of such variable, referred to as transition function and, fluctuates between extreme regimes (González et al., 2005). The fact that the tran-sition variable is cross section-specific and time-varying implies that the regression coefficients for each of the cross-sections in the panel are changing over time. A simple PSTR model with two extreme re-gimes and a single transition function can be defined as:

$y_{i t}=\mu_{i}+\beta_{0}^{\prime} x_{i t}+\beta_{1}^{\prime} x_{i t} g\left(q_{i t} ; \gamma, c\right)+\varepsilon_{i t}$

where $i=1, \ldots, N, t=1, \ldots, T$, and $N$ and $T$ denote the cross-section and time-dimension of the panel, respectively. The dependent variable $y_{i t}$ (growth) is a scalar, $\mu_{i}$ represents the fixed country effects, $x_{i t}$ is $k$-dimensional vector of time-varying exogenous variables $(y 1$, gov, open_gfff and pvtcrd_inst), $q_{i t}$ is the threshold variable (infltx), $c$ is the threshold parameter (inflation threshold) and, $\varepsilon_{i t}$ is the residual term. The slope parameter $\gamma$ denotes the smoothness of the transition from one regime to the other. As $\gamma \rightarrow \infty$, the transition function approaches an indicator function $I\left(q_{i t}>c_{j}\right)$ that takes the value of 1 if $q_{i t}>c_{j}$. As $\gamma \rightarrow 0$, the transition function becomes a homogenous or linear panel regression model with fixed effects. Ibarra and Trupkin (2011) point out that if $\gamma$ is sufficiently high, then the PSTR model reduces to a threshold model with two regimes as in Khan and Senhadji (2001). Therefore, in such a case, the direct effect of inflation on economic growth will be given by $\beta_{0}^{\prime}$ for those countries with inflation less than or equal to $c_{j}$, and by $\beta_{0}^{\prime}+\beta_{1}^{\prime}$ for those countries where inflation exceeds $c_{j}$.

The transition function $g\left(q_{i t} ; \gamma, c\right)$ is a continuous function of the observable variable $q_{i t}$ and is normalised to be bounded between 0 and 1 ; and these extreme values are associated with regression coefficients $\beta_{0}^{1}$ and $\beta_{0}^{\prime}+\beta_{1}^{\prime}$. In general, the value of $q_{i t} q_{i t}$ In general, the value of $g\left(q_{i t} ; \gamma, c\right)$ and thus the effects of inflation on growth:

$e_{i t}=\frac{\triangle y_{i t}}{\Delta x_{i t}}=\beta_{0}^{\prime}+\beta_{1}^{\prime} g\left(q_{i t} ; \gamma, c\right)$ forcountry $i$ atperiod $t$.

We follow Granger and Teräsvirta (1993), Teräsvirta (1994), Jansen and Teräsvirta (1996), and González et al. (2005) and consider the following logistic transition function:

$g\left(q_{i t} ; \gamma, c\right)=\left[1+\exp \left(-\gamma \prod_{j=1}^{m}\left(q_{i t}-c_{j}\right)\right]^{-1}\right.$

where $c=\left(c_{1}, \ldots, c_{m}\right)^{\prime}$ is an $m$-dimensional vector of location parameters, and $\gamma>0$ and $c_{1} \leq c_{2} \leq, \ldots, c_{m}$ are identification restrictions. The 
PSTR model can be generalised to allow for more than two different regimes as follows:

$y_{i t}=\mu_{i}+\beta_{0}^{\prime} x_{i t}+\sum_{j=1}^{r} \beta_{j}^{\prime} x_{i t} g_{j}\left(q_{i t}^{j} ; \gamma_{j}, c_{j}\right)+\varepsilon_{i t}$

where the transition functions $g_{j}\left(q_{i t}^{j} ; \gamma_{j}, c_{j}\right), j=1, \ldots r$ depend on the slope parameters $\gamma_{j}$ and on location parameters $c_{j}$. I f $r=1, q_{i t}^{j}=q_{i t}$, and $\gamma_{j} \rightarrow \infty$ for all $j=1, \ldots r$, the transition function becomes an indicator function, with $I[A]=1$ if event $A$ occurs, and $I[A]=0$ otherwise; then the model in Eq. (4) becomes a PTR model with $r+1$ regimes. Therefore this multi-level PSTR can be viewed as generalisation of the multiple regime PTR in Hansen (1999).

\subsubsection{Testing for linearity}

González et al. (2005) outlined a procedure for testing linearity against a PSTR model. This is deemed important since the PSTR is not identified if the data-generating process (DGP) is linear, therefore a linearity test is viewed to be necessary to avoid the estimation of unidentified models. The null hypothesis is: $H_{0}: \beta_{1}=0$. However, the test is non-standard because under this null hypothesis, the PSTR model contains unidentified nuisance parameters (Hansen, 1996). Therefore, we adopt a possible solution developed by Luukkonen et al. (1988) and replace the transition function $g\left(q_{i t} ; \gamma, c\right)$ byitsfirst-order Taylor expansion around $\gamma=0$ and test the linearity hypothesis as $H_{0}: \gamma=0$. After reparameterization, this leads to the following auxiliary regression:

$y_{i t}=\mu_{i}+\beta_{0}^{\prime *} x_{i t}+\beta_{1}^{\prime *} x_{i t} q_{i t}+\ldots+\beta_{m}^{\prime *} x_{i t} q_{i t}^{m}+\varepsilon_{i t}^{*}$

where the parameter vectors $\beta^{\prime}{ }_{1}{ }^{*}, \ldots, \beta_{m}^{\prime}{ }^{*}$ are multiples of $\gamma$ and $\varepsilon_{i t}{ }^{*}=$ $\varepsilon_{i t}+R_{m} \beta_{1}{ }^{*} x_{i t}$, w h e r e $R_{m}$ is the remainder of the Taylor expansion. Therefore testing $H_{0}: \gamma=0$ in Eq. (1) is equivalent to testing the $H_{0}{ }^{*}: \beta^{\prime}{ }_{1}{ }^{*}=\ldots=\beta^{\prime}{ }_{m}{ }^{*}=0$ in Eq. (5). Then standard tests can be applied. We follow Colletaz and Hurlin (2006) and use Wald, Fischer and Likeli-hood ratio tests.

The Wald LM test can be written as:

$L M_{W}=\frac{N T\left(S S R_{0}-S S R_{1}\right)}{S S R_{0}}$

where $K$ is the number of explanatory variables, $S S R_{0}$ is the panel sum of squared residuals under $H_{0}$ (linear panel model with individual effects) and $S S R_{1}$ is the panel of sum of squared residuals under $H_{1}$ (PSTR model with $m$ regimes).

The Fischer LM test can be written as:

$L M_{F}=\frac{N T\left(S S R_{0}-S S R_{1}\right) / m k}{S S R_{0} /(T N-N-m k)}$

with an approximate distribution of $F(m k, T N-N-m k)$.

The likelihood ratio test can be written as:

$L R=-2\left[\log \left(S S R_{1}-\log \left(S S R_{0}\right)\right.\right.$.

All these linearity tests are distributed $\chi^{2}(K)$ under the null hypothesis.

\subsubsection{Testing for the number of transition functions}

According to Teräsvirta (1994) linearity tests also serve to determine the appropriate order of $m$ of the logistic transition function in Eq. (3) or equivalently the order of extreme regimes. We therefore test the null of no remaining non-linearity in the transition function. Consider an auxiliary regression (Eq. (5)) with $r=2$ or three regimes:

$y_{i t}=\mu_{i}+\beta_{0}^{\prime *} x_{i t}+\beta_{1}^{* *} x_{i t} g_{1}\left(q_{i t}^{1} ; \gamma_{1}, c_{1}\right)+\beta_{2}^{\prime *} x_{i t} g_{2}\left(q_{i t}^{2} ; \gamma_{2}, c_{2}\right)+\varepsilon_{i t}^{*}$
The null hypothesis of no remaining heterogeneity in an estimated three-regime PSTR model can be formulated as $H_{0}: \gamma_{2}=0$ in Eq. (9). However, as already indicated, this test is non-standard because under this null hypothesis, the PSTR model contains unidentified nuisance parameters. Therefore, this identification problem is circumvented by replacing transition function, $g_{2}\left(q_{i t}^{2} ; \gamma_{2}, c_{2}\right)$ by the Taylor expansion around $\gamma_{2}=0$, resulting in the following auxiliary regression:

$y_{i t}=\mu_{i}+\beta_{0}^{*} x_{i t}+\beta_{1}^{* *} x_{i t} g_{1}\left(q_{i t}^{1} ; \gamma_{1}, c_{1}\right)+\theta x_{i t} q_{i t}++\varepsilon_{i t}^{*}$.

Using the auxiliary regression (Eq. (10)) with $r=2$, testing the null hypothesis of no remaining non-linearity is defined as $H_{0}: \theta=0$. Denote $S S R_{0}$ as the panel sum of squared residuals under $H_{0}$ (i.e. in a PSTR model with one transition function), and $S S R_{1}$ as the sum of squared residuals of the transformed model (Eq. (10)). Given a PSTR with $r^{*}$ transition functions, the procedure is as follows; test $H_{0}: r=r^{*}$ against $H_{1}: r=r^{*}+1$. If $H_{0}$ is not rejected, then the procedure ends. Otherwise, the null hypothesis $H_{0}: r=r^{*}+1$ is tested against $H_{1}: r=r^{*}$ +2 . The testing procedure continues until the first accep-tance of the null hypothesis of no remaining heterogeneity. It should be kept in mind that at each step of the sequential procedure, the sig-nificance level must be reduced by a constant factor $\tau$, such as $0<\tau<1$ in order to avoid excessively large models. As suggested by González et al. (2005), we assume $\tau=0.5$.

\subsection{The data}

We use annual data obtained from the World Bank Development Indicators (WDI), IMF International Financial Statistics (IFS), Penn World Tables (PWT) and Polity IV, for the period 1980 to 2008. The growth and inflation variables used in the analysis are growth in real GDP (growth) and inflation tax (infltx), respectively. We follow, amongst others, the work of Levine and Renelt (1992) and also Durlauf et al. (2005) in choosing a set of variables that controls for other factors associated with economic growth. However, in addition to the variables used in chapter two, a measure of conditional convergence namely, initial level of income $(y 1)$ is included as part of the explanatory variables. The other control variables include the ratio of gross fixed capital formation to GDP ( $g f c f$ ), ratio of imports and exports to GDP (open), a measures of financial development - the ratio of private sector credit extension to GDP (pvtcrd), an institution-al variable, representing a measure of the level of political rights in the country/level of democracy (inst), and a measure of the size of the government (gov). Moreover, we interact openness with gross fixed capital formation in order to capture the notion that more open economies tend to encourage higher domestic investment with-in the country (open_gfcf), which is expected to induce higher eco-nomic growth. Private sector credit extension is also interacted with the level of institutional freedom to reflect that deepness of financial development is also induced by more free and independent institutions in the economy (pvtcrd_inst). Variable descriptions are presented in Table 1.

Data on a number of variables such as black market exchange rate premium, corruption perception index, and others were also considered as potential explanatory variables. However, these were dropped from the analysis, due to statistical insignificance and/or lack of data for some countries in the sample. Four SADC member countries, in particular Angola, Democratic Republic of Congo, Seychelles and Zimbabwe were dropped from the analysis due to data unavailability. Therefore, the number of countries included in the sample remains at eleven.

Table 2 depicts the correlation among the variables. As expected, inflation and economic growth presents a negative and statistically significant relationship at the $5 \%$ significance level. In terms of the control variables the measure of the size of the government (gov) had an unexpected positive sign although not statistically significant. 
The interaction variable of private sector credit extension as a share of GDP and institutions (pvtcrd_inst) has an expected positive sign but is also not statistically significant. Initial level of income (y1) and an interaction variable between openness as a share of GDP and gross fixed capital formation as a share of GDP (open_gfcf), both have expected signs and are statistically significant. Therefore, this preliminary inspection of data shows that a negative relationship between inflation and economic growth in the SADC region indeed exists as expected. Descriptive statistics are presented in Table 3.

Table 3 shows that on average, inflation tax in the SADC region is around $14 \%$ and the economic growth rate is around $4 \%$ for the period 1980-2008. The highest economic growth rate may be attributable to the faster growth rate that was experienced in Lesotho in the late 1990s due to the construction of dams, roads and other infrastructure as part of the Lesotho Highlands Water Project.

Panel unit root tests were also conducted using both the Im et al. (2003) and the Levin, Lin and Chu (2002) (LLC) specifications. The LLC test assumes parameter homogeneity, meaning that suffers from heterogeneity bias as opposed to the IPS which allows for individual unit root processes and thus heterogenous parameters. Therefore, IPS is the preferred test. However, LLC unit root test results confirm IPS test results, with the exception of the pvtcrd_inst variable, where the IPS sta-tistic indicates that the panel is non-stationary, while the LLC test finds the panel stationary. All other variables are stationary, with the excep-tion of government expenditure variable (gov) which is only stationary in first differences (Table 4 ).

\section{Empirical results}

\subsection{Linearity and no remaining non-linearity results}

The linearity tests results are presented in Table 5 and show that the null hypothesis that the model is linear is rejected for all three tests, implying that the relationship between inflation and growth in the SADC region is indeed nonlinear.

Table 6 presents the test for no remaining non-linearity after assuming a two-regime model. The results indicate that the null hypothesis cannot be rejected, implying that the model has only one threshold or two regimes. Thus implies that in the SADC region, there is only one threshold level of inflation which separates the low inflation regime and high inflation regime.

Table 1

Variable description.

\begin{tabular}{|c|c|c|}
\hline Variable & Description & Source \\
\hline cpi & Consumer price index & IFS \\
\hline$g f c f$ & Gross fixed capital formation as a share of GDP & WDI \\
\hline gov & $\begin{array}{l}\text { Government expenditure as a share of GDP [government } \\
\text { expenditures/nominal GDP - calculated from WDI data] }\end{array}$ & $\begin{array}{l}\text { Own } \\
\text { calculation }\end{array}$ \\
\hline$g d p$ & Nominal GDP (national currency; millions) & WDI \\
\hline $\operatorname{rgdp}$ & Real GDP (national currency; millions) & WDI \\
\hline growth & Growth of real GDP & $\begin{array}{l}\text { Own } \\
\text { calculation }\end{array}$ \\
\hline infl & Annual inflation rate (annual growth rate of CPI) & IFS \\
\hline infltx & Inflation tax $[$ infl/(1+infl $)]$ & $\begin{array}{l}\text { Own } \\
\text { calculation }\end{array}$ \\
\hline inst & $\begin{array}{l}\text { Institutional variable (as measured by polity2 in polity } \\
\text { IV dataset) }\end{array}$ & $\begin{array}{l}\text { PolityIV } \\
\text { Database }\end{array}$ \\
\hline$y 1$ & $\begin{array}{l}\text { Initial level of income, taken as the lagged value of real } \\
\text { GDP }[y 1=\operatorname{rgdp}(-1)]\end{array}$ & $\begin{array}{l}\text { Own } \\
\text { calculation }\end{array}$ \\
\hline open & Exports + imports as share of GDP & WDI \\
\hline crd & $\begin{array}{l}\text { Private sector credit extension (national currency; } \\
\text { millions) }\end{array}$ & IFS \\
\hline pvtcrd & $\begin{array}{l}\text { Private sector credit extension as share of GDP } \\
{[p v t c r d=c r d / g d p]}\end{array}$ & $\begin{array}{l}\text { Own } \\
\text { calculation }\end{array}$ \\
\hline open_gfff & open $\times g f f f$ & $\begin{array}{l}\text { Own } \\
\text { calculation }\end{array}$ \\
\hline pvtcrd_inst & pvtcrd $\times$ inst & $\begin{array}{l}\text { Own } \\
\text { calculation }\end{array}$ \\
\hline
\end{tabular}

Table 2

Correlation matrix for 11 SADC countries (1980-2008).

\begin{tabular}{lclllll}
\hline & Growth & infltx & $y 1$ & gov & open_gfff & pvtcrd_inst \\
\hline Growth & 1 & & & & & \\
infltx & $-0.12^{* *}$ & 1 & & & & \\
$y 1$ & $-0.13^{*}$ & 0.09 & 1 & & & \\
gov & 0.02 & $-0.29^{* * *}$ & $-0.47^{* * *}$ & 1 & & \\
open_gfff & $0.23^{* * *}$ & -0.01 & 0.16 & 0.06 & 1 & \\
pvtcrd_inst & 0.05 & $-0.31^{* * *}$ & $-0.13^{*}$ & $0.19^{* * *}$ & 0.06 & 1
\end{tabular}

*** $/ * *{ }^{*}$ denote significance at $1 \%, 5 \%$ and $10 \%$, respectively. All the variables are expressed in logarithmic form except for the institutional variable (inst) since it ranges from -7 to +7 .

\subsection{Model estimation results}

Estimated model parameters are presented in Table 7. In line with expectations, the threshold level is found to be a double-digit figure of $18.9 \%$ for the SADC region, which is similar to the findings of $19.2 \%$, $19.1 \%$ and $19.6 \%$ found by Drukker et al. (2005), Ibarra and Trupkin (2011), and Mignon and Villavicencio (2011), respectively for a number of other developing regions. This estimated threshold level exceeds the findings by Khan and Senhadji (2001), a n d Moshiri and Sepehri (2004) where both studies report a threshold level of $11 \%$ for developing countries.

Similarly, Espinoza et al. (2010) and Schiavo and Vaona (2007), r e port threshold values of 10 and $12 \%$, respectively. However, the fact that the estimated threshold level is at double-digits and also falls with-in the 10 to $20 \%$ bracket, similar to the studies mentioned above, may be attributable to the notion that SADC member countries, as being classified under non-industrialised, low income, or developing countries share similar economic characteristics and pursue similar macroeconomic policies as other developing regions around the world, hence the economic conditions may be similar. In particular, many developed countries across the world, such as New Zealand and United Kingdom, have all adopted an inflation targeting monetary policy framework, which clearly states the mandate of central banks as containing inflation at particular level(s) or within certain range(s). However, in Africa com-prising mainly of developing countries, only two countries namely, Ghana and South Africa have adopted inflation targeting monetary pol-icy frameworks. Hence some macroeconomic conditions in the SADC region are similar to the conditions transpiring in developing countries elsewhere.

All the coefficients, with the exception of the coefficient for initial level of income $(y 1)$ are statistically significant in the high inflation regime. The signs of coefficients are all consistent with empirical growth literature. The coefficient for the threshold variable (infltx) is negative for both regimes, but statistically insignificant for the low inflation rate regime $\left(\beta_{0}\right)$ and statistically significant for the high inflation rate regime $\left(\beta_{1}\right)$. This means that the effect of inflation on economic growth is not statistically significant when the inflation rate is below the threshold level of $18.9 \%$ but significant when it is above the threshold

Table 3

Descriptive statistics.

\begin{tabular}{lllllll}
\hline & Growth & infltx & $y 1$ & gov & open_gfcf & pvtcrd_inst \\
\hline Mean & 0.04 & 0.14 & $476,491.1$ & 0.31 & 7.47 & 1.88 \\
Median & 0.04 & 0.10 & $22,798.4$ & 0.19 & 10.25 & 0.07 \\
Maximum & 0.19 & 0.98 & $3,559,245$ & 3.03 & 17.79 & 29.19 \\
Minimum & -0.15 & -0.01 & 1806.2 & 0.07 & -1.22 & -2.64 \\
Std. dev. & 0.05 & 0.13 & $809,127.3$ & 0.38 & 6.20 & 5.39 \\
Skewness & -0.17 & 3.06 & 1.85 & 3.81 & -0.23 & 3.42 \\
Kurtosis & 5.03 & 14.71 & 5.38 & 20.78 & 1.38 & 14.89 \\
Jarque-Bera & 57.30 & 2359.0 & 222.9 & 5051.7 & 38.2 & 2538.1 \\
Probability & 0.00 & 0.02 & 0.00 & 0.00 & 0.00 & 0.00 \\
\# of obs. & 324 & 324 & 324 & 324 & 324 & 324 \\
\# of countries & 11 & 11 & 11 & 11 & 11 & 11 \\
\hline
\end{tabular}


Table 4

Panel unit root tests.

\begin{tabular}{|c|c|c|c|c|c|c|}
\hline & Growth & infltx & $y 1$ & gov & open_gfcf & pvtcrd_inst \\
\hline \multicolumn{7}{|l|}{ IPS W-stat } \\
\hline Levels & $-4.91^{* * *}$ & $-3.28^{* * *}$ & $-93.7^{* * *}$ & 0.27 & $-1.62^{* *}$ & -0.92 \\
\hline [P-value $]$ & [0.00] & [0.00] & [0.00] & {$[0.61]$} & {$[0.05]$} & {$[0.18]$} \\
\hline Differences & $-8.77^{* * *}$ & $-10.00^{* * *}$ & $-140.0^{* * *}$ & $-6.83^{* * *}$ & $-10.13^{* * *}$ & $-7.19^{* * *}$ \\
\hline [P-value] & {$[0.00]$} & [0.00] & {$[0.00]$} & {$[0.00]$} & {$[0.00]$} & {$[0.00]$} \\
\hline \multicolumn{7}{|l|}{ LLC $t^{*}$-stat } \\
\hline Levels & $-2.89^{* * * *}$ & $-1.98^{* *}$ & $-64.2^{* * *}$ & -0.60 & $-1.39^{*}$ & $-1.66^{* *}$ \\
\hline [P-value $]$ & [0.00] & [0.02] & [0.00] & {$[0.27]$} & {$[0.08]$} & {$[0.05]$} \\
\hline Differences & $-8.64^{* * *}$ & $-9.94^{* * *}$ & $-201.9^{* * *}$ & $-6.66^{* * *}$ & $-10.08^{* * *}$ & $-6.07^{* * *}$ \\
\hline [P-value $]$ & [0.00] & {$[0.00]$} & [0.00] & {$[0.00]$} & {$[0.00]$} & {$[0.00]$} \\
\hline
\end{tabular}

******/* denote significance at $1 \%, 5 \%$ and $10 \%$, respectively. [P-values] are in brackets.

level. These results are similar as those of Ibarra and Trupkin (2011). The coefficient associated with the initial level of income $(y 1)$ is negative in both regimes but statistically significant in the low inflation regime. This may be an indication of conditional convergence in the SADC region when inflation rates are below the threshold level. These results are in line with those found by Chen and Gupta (2006) that there is convergence in the SADC region implying that poorer countries are able to catch up with the richer countries. Government spending is found to have a negative and significant impact on economic growth in high inflation regimes, indicating that higher levels of government spending do not necessarily lead to higher economic growth. Some level of government spending is necessary to maintain service levels and thus economic growth in a country. However, when channelled to-wards unproductive sectors or when expenditure mainly covers sala-ries and other current spending items, it will do little to enhance economic growth in a country. This is confirmed by the finding of Bittencourt (2012) that bigger governments tend to be detrimental to economic growth in four Latin American countries.

An interaction variable between private sector credit and an institu-tional variable (pvtcrd_inst), has a negative sign in the low inflation re-gime and a positive sign in the high inflation regime. This is unexpected since economic theory postulates that at low levels of inflation, and when institutions are free and independent from political pressure, more credit may be extended to the private sector and this may be growth enhancing (Levine and Renelt, 1992; T e m p le, 2000 ). Fur the r - more, at high inflation episodes, it is also expected that less credit may be extended to the private sector and this may hamper investment projects and this actually retards economic growth. The unexpected signs of the coefficients of this interaction variable in both low and high inflation rate regimes may be attributable to data limitations for the region. The coefficient associated with an interaction of openness and domestic investment (open_gfcf) is positive and statistically signif-icant in the low inflation regime indicating that more open economies tend to encourage domestic investment when inflation levels are low and this is also growth enhancing. However, the coefficient is negative and statistically significant in the high inflation regime indicating that high inflation tends to discourage domestic investment and this retards economic growth. Fig. 1 shows the transition function plotted against the inflation rate.

From Fig. 1 it is evident that the change from a low inflation regime to a high inflation regime is entirely smooth but relatively rapid. This is indicated by the estimated high transition parameter of 77.37. Ibarra

Table 5

Linearity tests.

\begin{tabular}{lcl}
\hline Test & Statistic & $P$-value \\
\hline Lagrange multiplier - Wald $\left(\mathrm{LM}_{\mathrm{W}}\right)$ & 26.969 & 0.003 \\
Lagrange multiplier - Fischer $\left(\mathrm{LM}_{\mathrm{F}}\right)$ & 2.771 & 0.003 \\
Likelihood ratio $(\mathrm{LR})$ & 28.586 & 0.000 \\
\hline
\end{tabular}

$H_{0}$ : linear model; $H_{1}$ : PSTR model with at least one threshold. and Trupkin (2011) point out that if a transition parameter is high, then the PSTR model reduces to a threshold model of two regions as in Khan and Senhadji (2001). The estimated threshold value of $18.9 \%$ points to the half way point of the transition.

\section{Conclusion}

Many central banks in various countries have adopted an inflation targeting monetary policy framework in recent years so as to control the level of inflation. In doing so, these countries determined the threshold level of inflation exogenously. This paper, however, revisits the inflation-growth nexus by applying a smooth transition regression model for panel data (PSTR) which precisely determines the threshold level of inflation endogenously, hence an important advantage of the PSTR over the alternative models that have been used to estimate such a relationship. In particular, the paper estimates the threshold level of inflation in the SADC region above which inflation is detrimental to economic growth. This relatively new panel data econometric technique also estimates the smoothness of the function that links one regime (low) to another regime (high).

The test for non-linearity provides evidence that the inflationgrowth relationship in the SADC region is non-linear. Therefore, this warrants the use of PSTR in order to estimate this nexus. The test for

Table 6

Tests of no remaining non-linearity (test for the number of regimes).

\begin{tabular}{lcl}
\hline Test & Statistic & $P$-value \\
\hline Lagrange multiplier - Wald $\left(\mathrm{LM}_{\mathrm{W}}\right)$ & 12.832 & 0.233 \\
Lagrange multiplier - Fischer $\left(\mathrm{LM}_{\mathrm{F}}\right)$ & 1.183 & 0.305 \\
Likelihood ratio $(\mathrm{LR})$ & 13.183 & 0.214 \\
\hline
\end{tabular}

$H_{0}$ : PSTR with one threshold; $H_{1}$ : PSTR with at least two thresholds.

Table 7

PSTR model estimation. Dependent variable: growth.

\begin{tabular}{cll}
\hline Variable & $\beta_{0}$ & $\beta_{1}$ \\
\hline infltx & -0.0971 & $-2.2903^{* * *}$ \\
& $(-0.3935)$ & $(-2.4380)$ \\
$y 1$ & $-0.0033^{* * *}$ & -0.0179 \\
& $(-1.9928)$ & $(-0.2343)$ \\
gov & -0.0878 & $-0.8255^{* * *}$ \\
& $(-0.5110)$ & $(-2.6839)$ \\
open_gfcf & $4.4143^{* * *}$ & $-0.7444^{* * *}$ \\
pvtcrd_inst & $(3.3919)$ & $(-2.2193)$ \\
Transition parameters & $-0.0079^{* * *}$ & $-0.0183^{* * *}$ \\
Threshold $(\mathrm{c})$ & $(-2.1351)$ & \\
Slope $(\gamma)$ & & $1.9891)$ \\
\hline
\end{tabular}

******** denote significance at the $1 \%, 5 \%$ and $10 \%$ levels, respectively. Values in parentheses are $t$-statistics based on standard errors corrected for heteroscedasticity. 


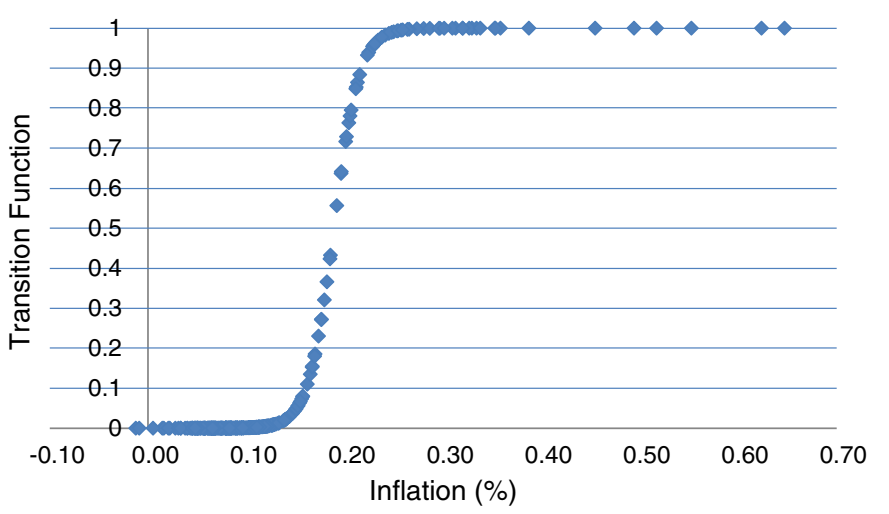

Fig. 1. Estimated transition function for SADC region.

no remaining non-linearity (number of regimes/thresholds) also reveals that a model with one threshold or two regimes adequately explains this nexus in the SADC region. The estimated coefficients associated with the control variables used in the model are also found to be consistent with the literature, with an exception of the interaction variable of private credit and institutional development (pvtcrd_inst). The threshold level of inflation is estimated at $18.9 \%$ which is in line with the findings by Drukker et al. (2005), Mignon and Villavicencio (2011) and Ibarra and Trupkin (2011), while marginally exceeding that of Khan and Senhadji (2001), Moshiri and Sepehri (2004), Espinoza et al. (2010) and Schiavo and Vaona (2007), which studies re-port threshold values of between 10 and $12 \%$.

In the SADC context, the estimated threshold level is also significantly higher than the $4 \%$ level estimated by Leshoro (2012) for South Africa. This is also higher than the $8 \%$ inflation threshold level that is found to be detrimental towards finance-growth activity for South African economy as estimated by Phiri (2010). This may be due to the fact that South Africa is the most developed country in the region and to a certain extent pursues different macroeconomic policies than the other SADC member countries. In particular, South Africa is the only country in the SADC region that has formally adopted an inflation targeting monetary policy framework, meaning that the South African Reserve Bank has a clear mandate of keeping the inflation rate within the $3-6 \%$ band. However, the other SADC countries do not have this clear mandate of keeping inflation rate within a particular target range; hence these countries may not be able to adequately control the rate of inflation when it is high. There-fore, given the above reasons, the estimated threshold level of infla-tion in the SADC region is at reasonable levels at $18.9 \%$.

The speed of the transition from a low to high inflation regime is relatively smooth but rapid, suggesting that central banks in the SADC region need to act immediately when the inflation rate is near or above the estimated threshold level.

In a nutshell, the findings reveal that although the SADC countries are striving towards common goals and also due to the fact that most of these countries have managed to reduce their inflation rates to single digits in recent years, these countries are still divergent in terms of their inflation rates and economic growth rates. As already mentioned, South Africa is the only country within the region which has formally adopted the inflation targeting monetary policy framework of 3-6\% and this is way below the estimated threshold level of $18.9 \%$ for the entire SADC region. Therefore, future research on the inflation-growth nexus in the region can focus on the context of smaller regional blocs such as Common Monetary Area (CMA) and Southern African Customs Union (SACU) and a lower threshold level may be expected. The CMA is a monetary and exchange rate arrangement between Lesotho, Namibia, South Africa and Swaziland. This arrangement resembles an asymmetric monetary union, with the bigger country - South Africa - being responsible for monetary policy formulation and implementation
(Alweendo, 2000). Therefore, the inflation-targeting monetary policy framework adopted by South Africa is in practice a de facto monetary policy framework for the CMA as a whole. South Africa may also be expected to have economic spill-over effects into the rest of the CMA.

It may also be interesting to investigate the inflation-growth nexus in the SACU context. The SACU agreement involves Lesotho, Botswana, Namibia, South Africa and Swaziland. The goods grown, produced or manufactured in the SACU, and imports from one member country to another, are free of customs duties and quantitative restrictions. However, these countries have common restrictions towards imports from the rest of the world. SACU also has free trade arrangements (FTA) with many trading blocs and countries around the world. Member countries are also allowed to have their bi-lateral trade arrangements with other blocs around the world. Therefore, since these countries have common external restrictions with the rest of the world, it would be interesting to investigate how this would affect the inflationary pressures and hence economic growth in such a region. Furthermore, in terms of future research, the study can also be expanded to incorporate the entire Sub-Saharan Africa (SSA) region and this would allow for cross-regional comparisons.

\section{References}

Alweendo, T.K., 2000. The Challenges of Monetary Policy for Namibia within the Common Monetary Arrangement. Welcome Address by the Governor, Mr. T.K. Alweendo of Bank of Namibia, 2nd Annual Bankers Conference, October, Windhoek, Namibia.

Bittencourt, M., 2012. Inflation and economic growth in Latin America: some panel time-series evidence. Economic Modelling 29 (2), 333-340.

Bruno, M., 1995. Does inflation really lower growth? Finance and Development 32 (3), 35-38.

Bruno, M., Easterly, W., 1998. Inflation crises and long-run growth. Journal of Monetary Economics 41, 3-26.

Chang, T., Chiang, G., 2011. Regime-switching effects of debt on real GDP per capita: the case of Latin America and Caribbean countries. Economic Modelling 28, 2404-2408.

Chen, P.-P., Gupta, R., 2006. An Investigation of Openness and Economic Growth in Using Panel Estimation. Department of Economics Working Paper Series 200622. University of Pretoria.

Colletaz, G., Hurlin, C., 2006. Threshold effect in the public capital productivity: an international panel smooth transition approach. University of Orleans working paper. Growth, Investment And Real Rates. Carneige-Rochester Conference Series on Public Policy 39, 95-140.

Drukker, D., Gomis-Porqueras, P., Hernandez-Verme, P., 2005. Threshold Effects in the Relationship Between Inflation and Growth: A New Panel-Data Approach. 11th International Conference on Panel Data.

Durlauf, S., Johnson, P., Temple, J., 2005. Handbook of economic growth-growth econometrics chapter 8. Part A 1, 555-677.

Eggoh, J., 2010. Financial development and growth: a panel smooth regression approach. Journal of Economic Development 35 (1), 15-33.

Eggoh, J., 2011. Inflation effects on finance-growth link: a panel smooth threshold approach. International Economic Journal http://dx.doi.org/10.1080/10168737.2011.631025.

Espinoza, R., Leon, H., Prasad, A., 2010. Estimating the inflation-growth nexus - a smooth transition model. IMF Working Paper WP/10/76.

Fischer, S., 1993. The role of macroeconomic factors in growth. Journal of Monetary Economics 32 (2), 485-512.

Furuoka, F., Mansur, K., Munir, Q., 2009. Inflation and economic growth in Malaysia: a threshold regression approach. ASEAN Economic Bulletin 26 (2), 180-193.

Ghosh, A., Phillips, S., 1998. Warning: inflation may be harmful to your growth. IMF Staff Papers 45 (4), 672-710.

González, A., Teräsvirta, T., van Dijk, D., 2005. Panel smooth transition regression models. Working Paper Series in Economics and Finance: Stockholm School of Economics (604).

Granger, C., Teräsvirta, T., 1993. Modelling Non-linear Economic Relationships. Oxford University Press.

Hansen, B., 1996. Inference when a nuisance parameter is not identified under the null hypothesis. Journal of Econometrics 64, 413-430.

Hansen, B., 1999. Threshold effects in non-dynamic panels: estimating, testing and inference. Journal of Econometrics 93, 345-368.

Heintz, J., Ndikumana, L., 2011. Is there a case for formal inflation targeting in subSaharan Africa? Journal of African Economies 20 (2), 67-103.

Hodge, D., 2006. Inflation and growth in South Africa. Cambridge Journal of Economics 30, $163-180$.

Ibarra, R., Trupkin, D., 2011. The relationship between inflation and growth: a panel smooth transition regression approach. Research Network and Research Centers Program of Banco Central del Uruguay (Working Paper).

Im, K., Pesaran, M., Shin, Y., 2003. Testing for unit roots in heterogeneous panels. Journal of Econometrics 115, 53-74.

Jansen, E., Teräsvirta, T., 1996. Testing parameter constancy and super exogeneity in econometric equations. Oxford Bulletin of Economics and Statistics 58, 735-763. 
Kan, E., Omay, T., 2010. Re-examining the threshold effects in the inflation-growth nexus with cross-sectionally dependent non-linear panel: evidence from six industrialised economies. Economic Modelling 27, 996-1005.

Khan, M., Senhadji, S., 2001. Threshold effects in the relationship between inflation and growth. IMF Staff Papers 48 (1).

Lee, C., Wong, Y., 2005. Inflationary threshold effects in the relationship between financial development and economic growth: evidence from Taiwan and Japan. Journal of Economic Development 30 (1), 49-69.

Leshoro, T., 2012. Estimating the Inflation Threshold for South Africa. University of South Africa Working Paper 285.

Levin, A., Lin, C.-F., Chu, C.-S., 2002. Unit root tests in panel data: asymptotic and finitesample properties. Journal of Econometrics 108 (1), 1-24.

Levine, R., Renelt, D., 1992. A sensitivity analysis of cross-country growth regressions. The American Economic Review 82 (4), 942-963.

Li, M., 2006. Inflation and Economic Growth: Threshold Effects and Transmission Mechanisms. University of Alberta Working Papers.

Luukkonen, R., Saikkonen, P., Teräsvirta, T., 1988. Testing linearity against smooth transition autoregressive models. Biometrika 75, 491-499.
Mignon, V., Villavicencio, A., 2011. On the impact of inflation on output growth: does the level of inflation matter? Journal of Macroeconomics 33, 455-464.

Moshiri, S., Sepehri, A., 2004. Inflation-growth profiles across countries: evidence from developing and developed countries. International Review of Applied Economics 18 (2), 191-207.

Phiri, A., 2010. At what level is inflation least detrimental towards finance-growth activity in South Africa? Journal of Sustainable Development in Africa 12, 6.

Pollin, R., Zhu, A., 2006. Inflation and economic growth: a cross-country non-linear analysis. Journal of Post Keynesian Economics 28 (4), 593.

Sarel, M., 1996. Non-linear effects of inflation on economic growth. IMF Staff Papers 43 (1), 199-215.

Schiavo, S., Vaona, A., 2007. Nonparametric and semiparametric evidence on the longrun effects of inflation on growth. Economics Letters 94, 452-458.

Temple, J., 2000. Inflation and Growth: Short Stories and Tall. Journal of Economic Surveys 14 (4).

Teräsvirta, T., 1994. Specification estimation and evaluation of smooth transition autoregressive models. Journal of the American Statistical Association 89, 208-218. 